\title{
Phenotypic and molecular characterization of Salmonella enterica serovar Sofia, an avirulent species in Australian poultry
}

Correspondence

Peter M. Smooker

peter.smooker@rmit.edu.au

Received 29 November 2010

Revised 23 December 2010

Accepted 27 December 2010

\author{
Emily Gan, Fiona J. Baird, Peter J. Coloe and Peter M. Smooker
}

School of Applied Sciences, RMIT University (Bundoora West), Plenty Road, Bundoora, Victoria 3083, Australia

\begin{abstract}
Salmonella enterica serovar Sofia (S. Sofia) is often isolated from chickens in Australia. However, despite its high frequency of isolation from chicken and chicken meat products, $S$. Sofia is rarely associated with animal or human salmonellosis, presumably because this serovar is avirulent in nature. The objective of this work was to investigate the phenotypic and molecular properties of $S$. Sofia in order to assess its pathogenic potential. Our in vivo studies support the observation that this serovar can colonize tissues, but does not cause disease in chickens. This was further confirmed with tissue culture assays, which showed that the ability of $S$. Sofia to adhere, invade and survive intracellularly is significantly diminished compared with the pathogenic Salmonella enterica serovar Typhimurium (S. Typhimurium) 82/6915. Molecular analysis of Salmonella pathogenicity islands (SPIs) showed that most of the differences observed in SPI1 to SPI5 of $S$. Sofia could be attributed to minor changes in the sequences, as indicated by a loss or gain of restriction cleavage sites within these regions. Sequence analysis demonstrated that the majority of virulence genes identified were predicted to encode proteins sharing a high identity (75-100\%) with corresponding proteins from S. Typhimurium. However, a number of virulence genes in S. Sofia have accumulated mutations predicted to affect transcription and/or translation. The avirulence of this serovar is probably not the result of a single genetic change but rather of a series of alterations in a large number of virulence-associated genes. The acquisition of any single virulence gene will almost certainly not be sufficient to restore $S$. Sofia virulence.
\end{abstract}

\section{INTRODUCTION}

Although a majority of Salmonella enterica serovars are pathogenic to humans and animals, their virulence varies from serovar to serovar. Salmonella usually causes gastroenteritis, with some serotypes [e.g. Salmonella enterica serovars Typhi and Typhimurium ( $S$. Typhi and $S$. Typhimurium)] able to cause enteric fever in humans and mice, respectively, and others such as Salmonella enterica serovars Dublin and Pullorum (S. Dublin and S. Pullorum) more likely to cause bacteraemia in their target animals (Fierer \& Guiney, 2001; Wallis, 2006). Salmonella spp. also have a wide variation in host range, from the ubiquitous serovars such as S. Typhimurium and Salmonella enterica serovar Enteritidis ( $S$. Enteritidis) to the host-restricted serovars [e.g. S. Dublin and Salmonella enterica serovar Choleraesuis ( $S$. Choleraesuis), both capable of causing infection in cattle, pigs and humans] and host-specific ones

Abbreviation: SPI, Salmonella pathogenicity island.

The GenBank/EMBL/DDBJ accession number for the SPI1 sequence of S. Sofia Bt8 is FJ496648.

Three supplementary figures and four supplementary tables are available with the online version of this paper. (e.g. S. Typhi and S. Pullorum, which are fully adapted to humans and chickens, respectively) (Fierer \& Guiney, 2001; Wallis, 2006). The pathogenicity of a serotype is determined by proteins encoded by various virulence genes; therefore, diversity can be attributed to genetic variation or polymorphisms in virulence genes.

Genes encoding virulence factors are usually found clustered together in distinct regions of bacterial chromosomes, termed pathogenicity islands (Hensel et al., 1995; Marcus et al., 2000). Salmonella pathogenicity islands (SPIs) are such regions, of which the most common and well studied are SPI1 to SPI5. These SPIs encode proteins that perform a wide variety of virulence-associated functions, such as translocation of effector proteins, host cell adhesion and invasion, intracellular survival and replication, and intestinal inflammation, all of which lead to gastroenteritis and/or systemic disease in the host (Chakravortty et al., 2005; Darwin \& Miller, 1999; Blanc-Potard \& Groisman, 1997; Blanc-Potard et al., 1999; Gerlach et al., 2007; Hensel, 2000; Hong \& Miller, 1998; Lawley et al., 2006; Morgan et al., 2004, 2007; Ochman et al., 1996; Wood et al., 1998; Wong et al., 1998).

SPIs have evolved by horizontal gene transfer events mediated by mobile genetic elements such as integrons, 
tranposons, insertion sequence (IS) elements and origins of replication (Gal-Mor \& Finlay, 2006; Hentschel \& Hacker, 2001; Marcus et al., 2000). The SPI regions may undergo genetic modifications (insertion and deletion events, mutations, etc.), generating the pathogenic diversity observed in Salmonella spp. It has been observed that naturally occurring insertions and deletions in the SPI regions of Salmonella isolates can affect the properties of the isolates, and render some serovars avirulent or unable to cause infection (Amavisit et al., 2003; Ginocchio et al., 1997; Hansen-Wester et al., 2004; Ochman \& Groisman, 1996; Porwollik et al., 2002).

Although frequently isolated from Australian poultry (Mellor et al., 2010), Salmonella enterica serovar Sofia (S. Sofia) does not cause disease in either humans or animals (Harrington et al., 1991; Heuzenroeder et al., 2001). The efficient colonization of a warm-blooded host such as the chicken is puzzling, as S. enterica subspecies II strains are usually associated with cold-blooded animals such as reptiles (Heuzenroeder et al., 2001). Little is known about the pathogenicity of $S$. Sofia. In vitro studies with HeLa, $\mathrm{CHO}$ and CEF-DF1 cell lines have shown low levels of invasion compared with the pathogenic S. Typhimurium $82 / 6915$, although the serovar was found to cause systemic disease in hosts (17-day-old embryonic chickens) with immature or immunocompromised immune systems (Rickard, 1998). An initial study by Heuzenroeder et al. (2001) revealed that $S$. Sofia has an incomplete inv region of SPI1. As these genes are involved in pathogenicity (Darwin \& Miller, 1999; Kimbrough \& Miller, 2000; Kubori et al., 1998, 2000; Sukhan et al., 2001), their mutation may contribute to the avirulence of $S$. Sofia.

Since $S$. Sofia is an efficient colonizer of chickens and is widespread amongst Australian poultry flocks, detailed studies are needed to gain a better understanding of the $S$. Sofia virulence process to assess its pathogenic potential. In this study, we carried out a phenotypic and molecular analysis of $S$. Sofia to further define its avirulent nature. In vitro and in vivo studies were used to assess the pathogenic potential of this serovar. In addition, the distribution of genes across the entire length of SPI1 to SPI5 in S. Sofia Bt8 was investigated. We compared all generated data with the corresponding virulence regions in $S$. Typhimurium 82/6915 (a known pathogenic strain). These findings will aid in understanding the virulence process of Salmonella spp. and provide insight into the avirulent phenotype of $S$. Sofia isolates in Australia.

\section{METHODS}

Bacterial and tissue culture growth conditions. Bacterial strains used in this study are listed in Table 1. Bacteria were grown on LuriaBertani (LB) agar or in LB broth and incubated aerobically at $37{ }^{\circ} \mathrm{C}$ for $16-18 \mathrm{~h}$, unless specified otherwise. $S$. Sofia strains were confirmed using the xylose lysine (XLD), ONPG and malonate tests (Lowe, 1962; Shaw \& Clarke, 1955). The following cell lines were used for in vitro analysis: a human intestinal epithelial cell line (INT407),

Table 1. Salmonella strains used in this study

\begin{tabular}{|c|c|c|c|}
\hline Serovar & $\begin{array}{c}\text { Strain } \\
\text { identification }\end{array}$ & $\begin{array}{c}\text { Location or } \\
\text { origin }^{\star}\end{array}$ & Source \\
\hline Agona & FSAW3463 & VIC & A. Lee $\dagger$ \\
\hline Enteritidis & 446302 & - & Biotechnology Laboratory, RMIT University \\
\hline Hadar & $\mathrm{P} 12$ & - & Biotechnology Laboratory, RMIT University \\
\hline Heidelberg & - & - & Biotechnology Laboratory, RMIT University \\
\hline Infantis & $999 S$ & SA & M. McKenzieł \\
\hline \multirow[t]{10}{*}{ Sofia } & Bt8 & VIC & M. McKenzie \\
\hline & 630MSC & VIC & \\
\hline & 988Q & QLD & \\
\hline & $786 \mathrm{CL}$ & QLD & \\
\hline & $554 \mathrm{NCA}$ & NSW & \\
\hline & $561 \mathrm{NC}$ & NSW & \\
\hline & 664SCA & SA & \\
\hline & $642 \mathrm{SC}$ & SA & \\
\hline & $242 \mathrm{~T}$ & TAS & \\
\hline & 140TCA & TAS & \\
\hline \multirow[t]{2}{*}{ Typhimurium } & SL1344 & - & R. Strugnell\$ \\
\hline & $82 / 6915$ & - & Biotechnology Laboratory, RMIT University \\
\hline Virchow & $370 \mathrm{QC}$ & QLD & M. McKenzie \\
\hline
\end{tabular}

${ }^{*}$ Origin of isolate: VIC, Victoria; NSW, New South Wales; QLD, Queensland; SA, South Australia; TAS, Tasmania; -, isolate origin unknown/information not available.

$†$ Food Science Australia, Werribee, Victoria, Australia.

¥Inghams Enterprises Pty Ltd, Springwood, Queensland, Australia.

§University of Melbourne, Victoria, Australia. 
chicken embryonic fibroblasts (CEF-DF1) and a murine macrophage cell line (J774A.1). All cell lines were grown and maintained in Dulbecco's modified Eagle's medium (DMEM; Invitrogen) containing $10 \%$ heat-inactivated new calf serum (NCS; Invitrogen) at $37{ }^{\circ} \mathrm{C}$ in a humidified $5 \% \mathrm{CO}_{2}$ incubator.

Adhesion, invasion and intracellular survival assays. Adhesion and invasion assays in INT407 and CEF-DF1 cells were carried out in 24-well tissue culture plates, as described by Elsinghorst (1994), with minor modifications. Both cell lines were seeded at a concentration of $3 \times 10^{5}$ cells per well and incubated overnight to obtain an $\sim 90 \%$ confluent monolayer. Infection was for 1 and $2 \mathrm{~h}$ (adherence and invasion assays, respectively) at an m.o.i. of 50-100 bacteria per tissue culture cell. After infection, wells were washed three times with PBS and incubated in media with $400 \mu \mathrm{g}$ gentamicin $\mathrm{ml}^{-1}$ (Sigma Aldrich) to kill any extracellular bacteria. The cells were then washed three times again with PBS, lysed with $0.25 \%$ Triton X-100, subjected to serial 10-fold dilutions, and plated on LB agar. Plates were incubated overnight at $37^{\circ} \mathrm{C}$ and bacteria were enumerated. Adherence assays were performed in the same manner without the gentamicin incubation step.

The ability of Salmonella isolates to survive intracellularly within macrophages was measured by the method outlined by Buchmeier \& Heffron (1989), with some modifications. Opsonized bacterial cells were added to 24 -well tissue culture plates with $4 \times 10^{5}$ macrophages per well at a ratio of 10-20 bacteria per macrophage. Phagocytosis was allowed to proceed for $20 \mathrm{~min}$ before cells were washed three times with PBS and incubated with $100 \mu \mathrm{g}$ gentamicin $\mathrm{ml}^{-1}$ for $1 \mathrm{~h}$. Cells were then rinsed three times with PBS and medium containing $10 \mu \mathrm{g}$ gentamicin $\mathrm{ml}^{-1}$ was added (time point $0 \mathrm{~h}$ ). Infected macrophages were sampled at $0,1,4$ and $24 \mathrm{~h}$ after infection by washing the cells with PBS and then lysing the macrophages with $0.25 \%$ Triton X-100. Appropriate dilutions were plated on LB agar plates to enumerate c.f.u.

Colonization of chickens. Newly hatched Cobb 500 broiler chicks were obtained from Inghams Farms, Pakenham, Victoria. Three groups of five chickens were colonized with $S$. Sofia Bt8 with an oral dose of $10^{8}$ c.f.u., and one group of five chickens was uncolonized. Faecal samples were taken for five consecutive days and enumerated, and chickens were observed twice daily for signs of abnormal behaviour. Faecal matter was suspended in LB broth, diluted and plated to Hektoen and XLD media in duplicate. Plates were incubated at $37{ }^{\circ} \mathrm{C}$ for 18-24 h. Standard microbiology methods were used to recover bacteria from the chicken organs (Cooper et al., 1992; Cox et al., 2007). At necropsy (21 days post-inoculation), each organ was removed aseptically and stored at $4{ }^{\circ} \mathrm{C}$ until processed. Each organ was processed within $8 \mathrm{~h}$ of necropsy. Samples were streaked onto the selective media Hektoen Enteric agar and XLD agar. Cloacal swabs were taken and streaked onto the same selective media. Caecal contents were diluted in LB broth and spread onto the same selective media.

Design of SPI primers. All primers were designed from $S$. Typhimurium LT2 sequences [GenBank accession nos NC_003197 (for SPI1), X99944, Y09357, AJ224892, U51927, Z95891, AJ224978 and X99945 (for SPI2), AF106566 (for SPI3), AJ576316 (for SPI4) and AE008747 (for SPI5)]. Sequences of the primers used in this study are given in Supplementary Tables S1-S3.

Restriction digestion and Southern transfer of genomic DNA. Genomic DNA was extracted using the cetyltrimethylammonium bromide (CTAB) method (Reichardt \& Rogers, 1994). Approximately 10-15 $\mu$ g genomic DNA from $S$. Typhimurium and $S$. Sofia isolates was digested at $37{ }^{\circ} \mathrm{C}$ for $16-18 \mathrm{~h}$ with $10 \mathrm{U}$ of the restriction enzymes $B g l I I, E c o$ RV and HindIII (Promega) or with $10 \mathrm{U}$ of a combination of these enzymes (BglII and EcoRV or HindIII and EcoRV). DNA fragments were subjected to electrophoresis in $1.0 \%$ agarose gels before being capillary-transferred and cross-linked onto Hybond-N membranes (Amersham Biosciences) for Southern hybridization. S. Typhimurium SL1344 was always included as a reference strain.

PCR amplification of SPI genes. DNA probes for Southern hybridization analysis were amplified using template DNA from $S$. Typhimurium SL1344. DNA probes and PCR products in the range 4.0-17 kb were amplified using the Expand Long Template PCR system (Roche Applied Science). Reactions were prepared in a $50 \mu 1$ volume containing $1 \times$ Expand Buffer System 3, $350 \mu \mathrm{M}$ dNTP mix, $0.4 \mu \mathrm{M}$ of each primer, $0.25 \mathrm{U}$ Expand Taq polymerase and 200400 ng template DNA. Amplification was carried out as described by Amavisit et al. (2003), with the amplification conditions adjusted depending on the annealing temperature and expected size of each PCR product (Supplementary Tables S1 and S2).

Amplification of PCR products less than $4.0 \mathrm{~kb}$ in length was carried out in a $25 \mu \mathrm{l}$ volume containing GeneAmp $1 \times$ PCR buffer (Applied Biosystems), $1 \times$ Q-solution (Qiagen), $2.5 \mathrm{mM} \mathrm{MgCl}, 200 \mu \mathrm{M}$ dNTP mix, $0.25 \mu \mathrm{M}$ of each primer, $0.25 \mathrm{U}$ AmpliTaq polymerase (Applied Biosystems) and 100-200 ng template DNA. PCR cycling conditions were as follows: $95^{\circ} \mathrm{C}$ for $5 \mathrm{~min}, 35$ cycles of $94{ }^{\circ} \mathrm{C}$ for $30 \mathrm{~s}$, appropriate annealing temperature for $1 \mathrm{~min}$ and $72{ }^{\circ} \mathrm{C}$ for $1 \mathrm{~min}$, with a final extension of $72{ }^{\circ} \mathrm{C}$ for $1 \mathrm{~min}$. The annealing temperatures and expected size of each PCR product are given in Supplementary Tables S1 and S2.

Southern hybridization. Southern blots of Salmonella isolates were processed using the DIG DNA Labeling and Detection kit (Roche Applied Sciences). DNA probes were labelled using the random primed method according to the manufacturer's protocol. After transfer of DNA, membranes were hybridized with the DIG-labelled probes at $65{ }^{\circ} \mathrm{C}$ in standard hybridization buffer $[5 \times$ SSC $(0.75 \mathrm{M} \mathrm{NaCl}$, $0.075 \mathrm{M}$ sodium citrate), $0.1 \%$ Sarkosyl (w/v), $0.02 \%$ SDS (w/v) and $1.0 \%$ blocking solution (w/v)] for 16-18 h. The blots were then washed twice in $2 \times$ SSC wash buffer [ $2 \times$ SSC, $0.1 \%$ SDS (w/v)] for $5 \mathrm{~min}$ each at room temperature, followed by two $15 \mathrm{~min}$ washes in $0.1 \times$ SSC wash buffer $[0.1 \times$ SSC, $0.1 \%$ SDS $(w / v)]$ at $68{ }^{\circ} \mathrm{C}$, and then subjected to anti-DIG detection as described by the manufacturer.

Sequencing of the SPI genes. PCR products were purified using the Geneclean kit (Bio 101 Systems) by following the manufacturer's instructions. Sequencing reactions were prepared and processed using the BigDye Terminator v3.1 Cycle Sequencing kit (Applied Biosystems) according to the manufacturer's protocol, and analysed by Micromon at Monash University, Melbourne, Australia. Isolate Bt8 was chosen as a reference $S$. Sofia strain for sequencing analysis by primer walking. Only SPI1 was sequenced with both forward and reverse primers (Supplementary Table S3); all the other SPIs were analysed by single-stranded sequencing (with either the forward or reverse primer). Potential mutation events in the SPI genes of $S$. Sofia Bt8 that were identified in the single-stranded sequence screen (by comparison with the corresponding gene sequence from $S$. Typhimurium SL1344) were confirmed by a subsequent PCR and sequence analysis of the region.

Data analysis. Southern hybridization patterns were analysed for differences in the RFLP pattern (by using SL1344 as a reference). Any differences observed in the $S$. Sofia isolates were subjected to further investigation by PCR and sequencing analysis. DNA sequences were assembled to produce a full-length SPI. The DNA sequence of each $S$. Sofia Bt8 SPI region was compared with the sequence of the corresponding S. Typhimurium LT2 SPI sequence (obtained from GenBank). A map of SPI1 to SPI5 of S. Sofia Bt8 was constructed based on the RFLP and sequence data. In addition, the putative protein sequence encoded by each Bt8 SPI gene was compared with the corresponding LT2 SPI proteins. 

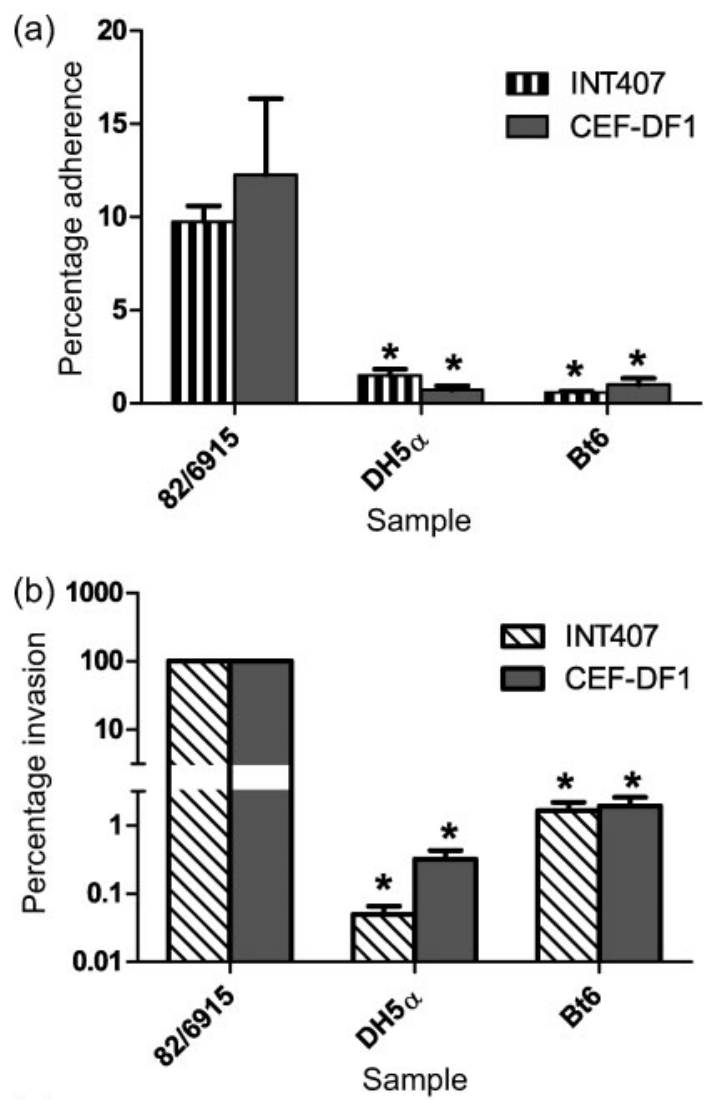

(c)

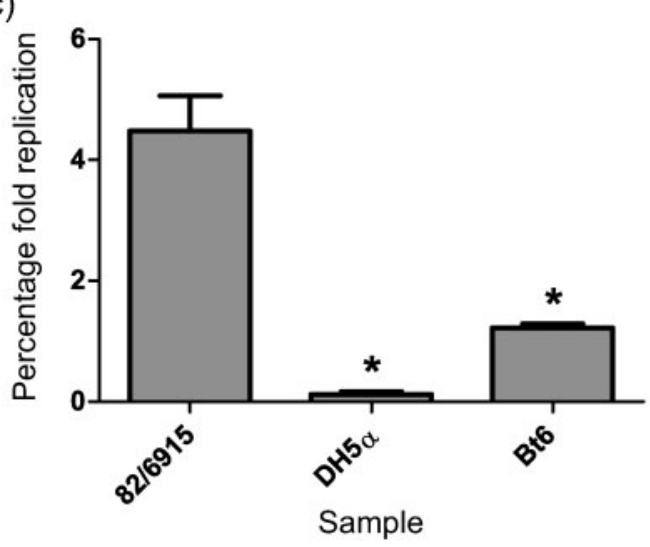

Fig. 1. Assessment of the adhesion, invasion, and intracellular survival and replication ability of $S$. Sofia. All experiments were carried out in triplicate at three different times, and data are shown as mean $\pm \operatorname{SEM}(n=9)$. Asterisks indicate values that are significantly altered compared with those of $S$. Typhimurium 82/6915 $(P<0.01)$. (a) Attachment to INT407 and CEF-DF1 cells. Adherence is expressed as a percentage of the number of adhered bacteria compared with the inoculum. (b) Invasiveness in INT407 and CEF-DF1 cells. Invasion is expressed as the percentage of invasive bacteria (number of invasive bacteria over initial number in the inoculum) relative to that of the pathogenic $S$. Typhimurium 82/ 6915 (taken as $100 \%$ ). (c) Survival and replication of S. Sofia in J774A.1 macrophages over $24 \mathrm{~h}$. Recovery of $S$. Sofia (as a percentage) is shown as the number of c.f.u. at $24 \mathrm{~h}$ post-infection over the number of c.f.u. at $0 \mathrm{~h}$ post-infection.

\section{RESULTS}

\section{S. Sofia is significantly less virulent than S. Typhimurium in cultured cells}

The ability of S. Sofia Bt8 to adhere to and invade INT-407 and CEF cells in comparison with the pathogenic $S$. Typhimurium 82/6915 and non-invasive Escherichia coli DH5 $\alpha$ was analysed. S. Sofia was found to have levels of adherence comparable with those of $E$. coli, but was significantly less adherent than $S$. Typhimurium (Fig. 1). Although slightly more invasive than the DH5 $\alpha$ strain, $S$. Sofia was recovered at significantly lower levels than the pathogenic $82 / 6915$ isolate $(\sim 1 \%$, see Fig. 1b). We also measured the ability of the strains to survive and replicate inside macrophages, as intramacrophage survival and replication have been shown to be an important part of the Salmonella pathogenic process (Darwin \& Miller, 1999; Ochman et al., 1996). S. Sofia was unable to survive and replicate in J774 cells, showing a 1.5-fold increase compared with the 4.5-fold increase observed in 82/6915 (Fig. 1). Similar levels of adherence, invasion and intramacrophage survival were observed with another $S$. Sofia isolate, $242 \mathrm{~T}$ (data not shown). Based on the in vitro data collected, it can be established that $S$. Sofia not only is inefficient at adhering to and invading cells but also is defective for macrophage survival and replication.

\section{S. Sofia colonizes chickens but causes no detectable signs of disease}

Each inoculated chicken showed minor signs of salmonellosis in the first 2 days, with faecal matter having a more watery appearance and consistency than prior to colonization. Feeding behaviour was normal and normal activity was observed. Faecal counts were followed for 5 days postinoculation. The highest level of $S$. Sofia recovered was at $24 \mathrm{~h}$ post-inoculation, at $1.32 \times 10^{8}$ c.f.u. $\mathrm{g}^{-1}$, and the lowest on the fifth day $(120 \mathrm{~h})$ post-inoculation, at $1.24 \times 10^{8}$ c.f.u. $\mathrm{g}^{-1}$. No chickens in the uninoculated group tested positive for $S$. Sofia. Twenty-one days after inoculation chickens were killed and examined. No signs of visual damage or loss of colour were observed for any organ removed from colonized chickens during necropsy. They were of normal size and shape for the chicken's age, and indistinguishable from those in uninoculated chickens, from which no $S$. Sofia was detected. In the inoculated chickens, S. Sofia was found in $26.67 \%$ of the caeca $(4 / 15), 46.67 \%$ of the cloacal swabs (7/15), $66.67 \%$ of the livers $(10 / 15)$ and $73.33 \%$ of the spleens (11/15). This would suggest that $S$. Sofia is capable of colonizing and spreading to chicken organs but is not able to cause infection or disease.

\section{Molecular comparison of SPI1 to SPI5 in S. Sofia reveals multiple changes}

S. Typhimurium isolates SL1344 and 82/6915 show identical restriction cleavage patterns (data not shown). 
Table 2. Summary of genetic changes in the SPIs of S. Sofia (in comparison with S. Typhimurium)

\begin{tabular}{|c|c|c|c|c|c|}
\hline SPI & $\begin{array}{c}\text { Total number } \\
\text { of genes }\end{array}$ & $\begin{array}{l}\text { Number of gene } \\
\text { insertions }\end{array}$ & $\begin{array}{l}\text { Number of genes } \\
\text { with no changes } \\
(100 \% \text { match })\end{array}$ & $\begin{array}{l}\text { Number of genes with } \\
\text { changes that may not affect } \\
\text { protein function } \dagger\end{array}$ & $\begin{array}{l}\text { Number of genes with } \\
\text { changes that possibly affect } \\
\text { protein function } \neq\end{array}$ \\
\hline 2 & $44(44)$ & - & - & 41 & 3 \\
\hline 3 & $12(11)$ & 1 & - & 6 & 5 \\
\hline 4 & $6(6)$ & - & - & 6 & - \\
\hline
\end{tabular}

${ }^{\star}$ The number of genes in the corresponding SPI of $S$. Typhimurium is indicated in parentheses.

$\dagger$ Changes include base insertion, deletion and/or substitution.

$\ddagger$ Changes include gene and base insertion, deletion and/or substitution.

Southern hybridization patterns (SPI1 to SPI5) obtained from different $S$. Sofia isolates were identical to one another and different from those of $S$. Typhimurium isolates (results not shown). Based on the sequence data, approximately $80 \%$ of the predicted $S$. Sofia effector proteins (Table 2) share $75-100 \%$ identity with the corresponding proteins from $S$. Typhimurium LT2 and are assumed to be functional orthologues. The changes observed in the remaining $20 \%$ of $S$. Sofia virulence genes (Table 2) are predicted to significantly alter the polypeptide sequence of the respective proteins, which almost certainly has functional implications.

Most differences observed across the length of SPI1 to SPI5 can be attributed to loss or gain of restriction cleavage sites, which resulted in differences in the RFLP patterns between S. Sofia and S. Typhimurium (Fig. 2 and Supplementary Fig. S4). However, several segments within the SPI1, SPI2, SPI3 and SPI5 regions in S. Sofia were observed to have accumulated changes predicted to affect gene expression (Fig. 2, Tables 2 and 3 and Supplementary Table S4). All changes (insertions, deletions and/or substitutions) seen in these regions were subjected to further analysis using Southern blotting, PCR amplification and genetic sequencing (when appropriate), and are compiled in Table 3. Large-scale changes in SPIs are depicted in Fig. 2, while the restriction patterns of SPIs 2 and 4 (in which no large deletions or insertions were seen) are depicted in Supplementary Fig. S3. All differences observed in SPI4 were attributable to the loss or gain of restriction sites, rather than to any insertions or deletions (see EcoRV restriction pattern in Supplementary Fig. S3). As the SPI4 proteins from $S$. Sofia Bt8 exhibited a 91-98\% match to their $S$. Typhimurium counterparts, this region is probably functional in S. Sofia.

\section{DISCUSSION}

The progress of Salmonella spp. infection varies depending on the infecting serovar and the type of host. Experimental infection and/or colonization of chickens with Salmonella has shown that the bacteria can colonize the intestinal tract before invading and spreading to internal organ sites, where systemic infection can occur (Chadfield et al., 2003; Chappell et al., 2009; Gast, 1994). This was observed in our colonization studies with $S$. Sofia, as consistently high levels of the bacteria (relative to the amount inoculated orally) were recovered from the faecal and cloacal samples, indicating that $S$. Sofia was present in the gastrointestinal tract post-inoculation. S. Sofia was also recovered from various chicken internal organs, particularly the liver and spleen. Both these organs appear to be important in the systemic disease process, as they are probably the internal sites in which pathogenic Salmonella spp. can multiply (Chappell et al., 2009). However, S. Sofia does not appear to follow the normal course of salmonellosis. The colonization by $S$. Sofia did not appear to cause infection or disease in the chickens, and this was further confirmed by the lack of morphological changes in or damage to the organs examined. Moreover, the avirulence of $S$. Sofia was also supported by the in vitro studies with human-, mouseand chicken-derived cell lines. S. Sofia was significantly less adherent and invasive, and was inefficient at intracellular survival and replication relative to the pathogenic $S$. Typhimurium 82/6915 (Fig. 1). Host cell invasion and intramacrophage survival and replication have been shown to be mediated by SPI genes (Darwin \& Miller, 1999; Marcus et al., 2000; Zhang et al., 2003), and the inability of $S$. Sofia to efficiently perform these virulence functions would indicate defects in this gene cluster.

Our molecular analysis confirmed this, and identified a relatively large number of changes in the SPIs between the virulent and avirulent serovars. The mutations observed in SPI1 ( $\operatorname{rgB} B, \operatorname{prgI}$, invJ and sipD) and SPI2 (ssaP, ssaI and $s s a E$ ) of $S$. Sofia appear to predominantly involve genes associated with the formation of a functional needle complex and the delivery of effector proteins into the host cell (Chakravortty et al., 2005; Darwin \& Miller, 1999; Kimbrough \& Miller, 2000; Kubori et al., 1998, 2000; Miki et al., 2009; Sukhan et al., 2001; Zierler \& Galán, 1995). A defective needle structure and delivery system would greatly affect the type III secretion system (T3SS) of the bacteria, inhibiting the translocation of proteins required 


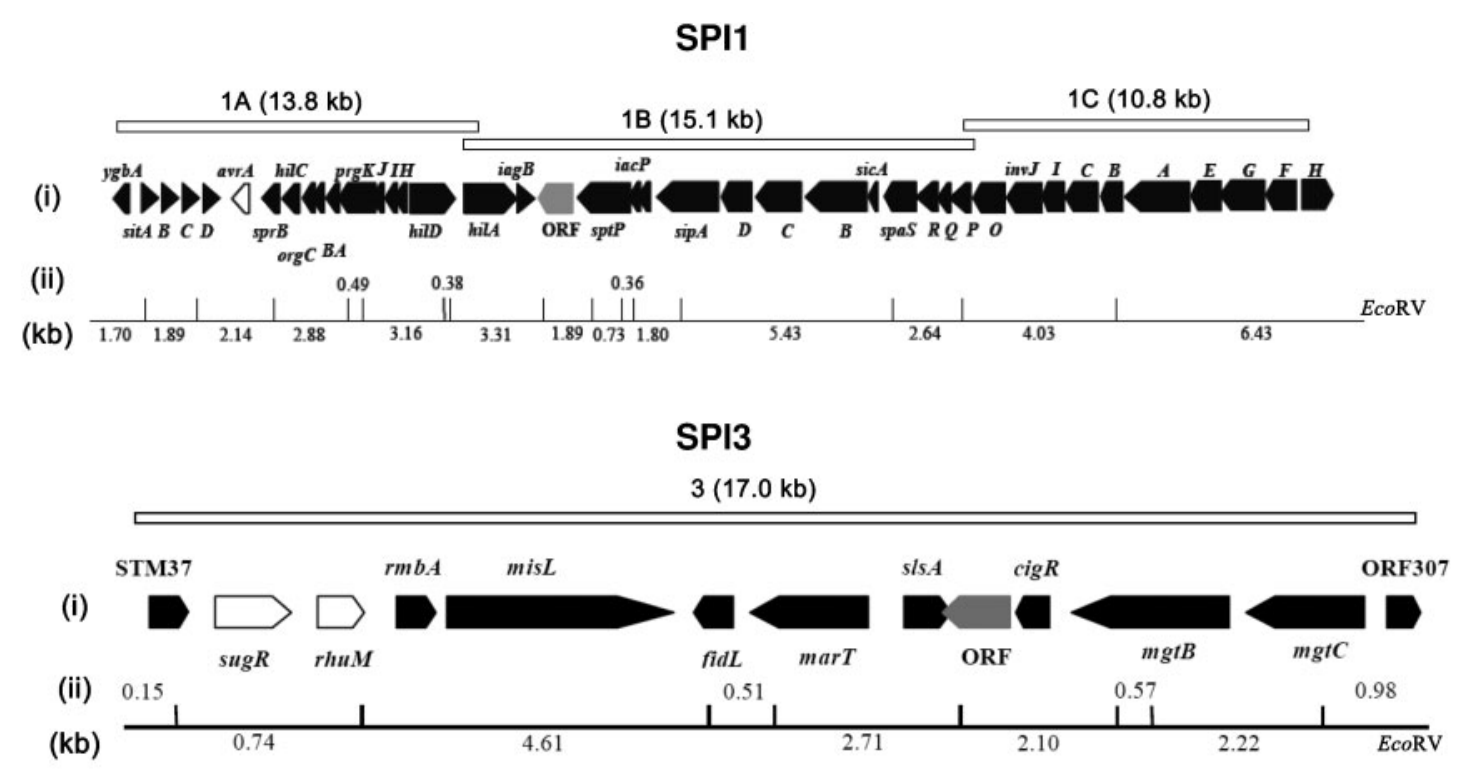

\section{SPI5}

(i)

(ii)

(kb)

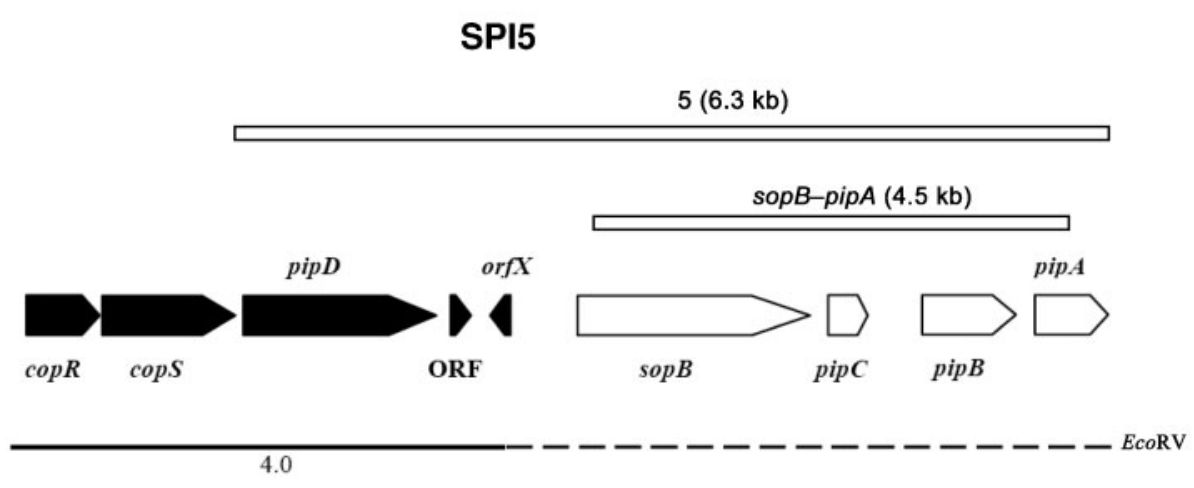

Fig. 2. Variation of SPI1-5 between S. Typhimurium SL1344 and S. Sofia Bt8, as determined by Southern hybridization, PCR restriction digestion and sequence analysis. For each SPI, (i) shows a schematic representation of the SPI gene and its direction of transcription (adapted from Amavisit et al., 2003). The absence of a gene or the presence of an insertion sequence (ORF) in $S$. Sofia is indicated as an unshaded block or a grey shaded box, respectively. DNA probes (the size and extent of each probe are shown) used for Southern hybridization are indicated above. For each SPI, (ii) shows an EcoRV restriction map for S. Sofia Bt8. The numbers indicate the sizes of detected fragments in kb. Maps are an estimate of the sizes of the restricted DNA fragments and are not drawn to scale.

for the pathogenic process. In addition, genetic changes were also found in SPI1 genes (sptP and avrA) encoding virulence effector proteins that perform functions such as rearrangement of the host cellular cytoskeleton (CollierHyams et al., 2002; Darwin \& Miller, 1999; Murli et al., 2001; Zhang et al., 2003). avrA, although deleted from SPI1, was present elsewhere in the genome (Table 2). Whether the encoded protein is functional in the absence of a T3SS is as yet unknown; however, it is considered unlikely. Interestingly, it has been shown that avrA, which encodes a cysteine protease responsible for inducing apoptosis, has variable expression amongst $S$. enterica serovars (Ben-Barak et al., 2006).

SPI1 and SPI2 are the most important pathogenicity islands in Salmonella spp., being involved in host invasion and systemic disease (Dieye et al., 2009; Klein \& Jones, 2001; Rychlik et al., 2009; Wood et al., 1998; Zhang et al., 2003), and the mutations observed in these two regions probably affect the virulence of this serovar. As we have shown, invasion is significantly reduced in S. Sofia, and no signs of disease were observed in colonized chickens.

SPI3 genes ( $\operatorname{mar} T$, misL and $s l s A$ ) have been shown to be involved in the systemic disease process and colonization in calves, mice and chickens (Dorsey et al., 2005; Lawley et al., 2006; Morgan et al., 2004; Rychlik et al., 2009; Tükel et al., 2007). Although their exact role in virulence processes has not been clearly defined, it is possible that the mutated protein products of these genes contribute to the avirulence of $S$. Sofia in poultry. Furthermore, proteins encoded by genes in the deleted SPI5 region are involved in intestinal 
Table 3. Variant SPI regions in S. Sofia Bt8 compared with those of S. Typhimurium SL1344 and LT2

\begin{tabular}{|c|c|c|}
\hline SPI & $\begin{array}{l}\text { Gene(s) } \\
\text { involved }\end{array}$ & Molecular analysis of SPI gene/region in S. Sofia Bt8 \\
\hline \multirow[t]{5}{*}{1} & avrA & $\begin{array}{l}\text { Analysis with primer pair sitD/F and sprB/R revealed that the sitD-sprB regions from Salmonella serovars } \\
\text { Typhimurium, Enteritidis, Infantis, Virchow and Agona were the expected } 2.3 \mathrm{~kb} \text {, while those obtained from all the } \\
S \text {. Sofia isolates were } 1.4 \mathrm{~kb} \text { in size (Supplementary Table S4). Sequence analysis of sitD-sprB revealed the } \\
\text { replacement of the avrA fragment with a } 0.28 \mathrm{~kb} \text { fragment harbouring an ORF encoding a protein of unknown } \\
\text { function, with } 98 \% \text { identity to the } 200 \mathrm{bp} \text { genetic element located in the sitD-sprB region of } S \text {. Typhi (GenBank } \\
\text { accession no. AF013575) and } S \text {. Choleraesuis (AF013574). Although missing from its expected location within SPI1, } \\
\text { Southern hybridization and PCR amplification showed that avrA was still present in the S. Sofia genome } \\
\text { (Supplementary Table S4) }\end{array}$ \\
\hline & ORF & $\begin{array}{l}\text { Presence of a } 1.2 \mathrm{~kb} \text { insertion between } i a g B \text { and } \operatorname{sptP} \text { (Fig. } 2 \text { ). The putative ORF is predicted to be a } 400 \text { aa protein } \\
\text { sharing sequence identity (up to } 96 \% \text { ) with a transposase from the mutator family. Only the } S \text {. Sofia isolates were } \\
\text { observed to contain this sequence between } i a g B \text { and } \operatorname{sptP} \text { (Supplementary Table S4) }\end{array}$ \\
\hline & $\operatorname{org} B$ & $\begin{array}{l}\text { Contains an additional } 10 \mathrm{bp} \text { sequence (ATCGTAAAAT) near the end of the reading frame, which (due to an in- } \\
\text { frame stop codon) results in a protein missing } 3 \text { aa (valine, isoleucine and arginine) from the end of the polypeptide } \\
\text { sequence }\end{array}$ \\
\hline & $\operatorname{prg} I$ & PrgI was observed to have an extra threonine residue at position 2 due to the insertion of CCA after the start codon \\
\hline & invJ & $\begin{array}{l}\text { Has a single A-T base substitution (ATG to GTG) at the start codon of invJ. Although GTG can serve as an initiation } \\
\text { codon in bacteria, if the start codon is inactivated by this mutation, then translation of invJ would start at the next } \\
\text { methionine codon, resulting in a protein missing the first } 52 \text { aa. There is also the possibility that initiation at GTG } \\
\text { would result in reduced expression }\end{array}$ \\
\hline \multirow[t]{3}{*}{2} & ssaP & Has a CCT deletion; predicted protein lacks a proline residue at position 45 \\
\hline & ssaI & $\begin{array}{l}\text { SsaI contains an additional arginine residue (position } 3 \text { within the protein) caused by the insertion of AGA within the } \\
\text { gene }\end{array}$ \\
\hline & $s s a E$ & $\begin{array}{l}\text { Has a deletion of } \sim 200 \mathrm{bp} \text { at the junction between } s s e A \text { and } s s a E \text { (Supplementary Fig. S4). In addition, a single base } \\
\text { substitution of } \mathrm{T} \text { to } \mathrm{C} \text { in } s s a E \text { interferes with the stop codon of this protein, resulting in five extra residues at the end } \\
\text { of the predicted polypeptide sequence (NKSLS) }\end{array}$ \\
\hline 3 & sugR and $r h u M$ & $\begin{array}{l}\text { PCR amplification showed that the } S \text {. Typhimurium and } S \text {. Enteritidis strains possess the specific } 4.88 \mathrm{~kb} \text { fragment } \\
\text { containing both the genes, which is missing from } S \text {. Sofia isolates (Supplementary Table S4). Further analysis of the } \\
\text { missing sugR-rhuM region revealed that it contains a } 135 \mathrm{bp} \text { nucleotide sequence sharing } 99 \% \text { identity with the } \\
\text { putative IS } 1351 \text { transposase (pseudogene) from } S \text {. Typhi CT18 (GenBank accession no. AL627280) }\end{array}$ \\
\hline \multirow[t]{3}{*}{3} & $s l s A$ & $\begin{array}{l}\text { Insertion of the } 1.2 \mathrm{~kb} \text { ORF noted above into } s l s A \text {. Sequence data revealed that this fragment is inserted towards the } \\
\text { end of } s l s A \text {, disrupting the stop codon for the protein. If translated, the predicted SlsA would have an additional } \\
25 \text { aa at the end of the polypeptide sequence }\end{array}$ \\
\hline & $m i s L$ & $\begin{array}{l}\text { Has a } 15 \mathrm{bp} \text { deletion (TCCCTGACCCTGTCG) from the middle of misL, resulting in a putative protein missing } 5 \text { aa } \\
\text { from the middle of the polypeptide sequence (VPDPV) }\end{array}$ \\
\hline & $\operatorname{mar} T$ & $\begin{array}{l}\text { Predicted MarT protein lacks the first } 23 \text { aa due to a genetic frameshift, resulting from the insertion of a } 10 \mathrm{bp} \\
\text { sequence (CGGGAGAAAC) about } 29 \mathrm{bp} \text { within the gene }\end{array}$ \\
\hline 5 & $s o p B-p i p A$ & $\begin{array}{l}\text { A series of primers designed to amplify different areas of SPI5 (Supplementary Tables S1 and S2) revealed that only } \\
\text { the } \operatorname{copR} \text {-orfX region (Fig. 2) yields specific PCR products. The deletion of the right half of this region (sopB, pipC, } \\
\text { pipB and } p i p A \text { ) was confirmed by Southern hybridization (with probe } \operatorname{sop} B-p i p A, \text { Fig. } 2 \text { ) and PCR amplification }\end{array}$ \\
\hline
\end{tabular}

secretory and inflammation responses, and mutations in these genes lead to attenuation and reduced virulence (Galyov et al., 1997; Morgan et al., 2004; Pfeifer et al., 1999; Wood et al., 1998). The inability of $S$. Sofia to induce intestinal inflammation and secretion, which are required to cause gastroenteritis, could be another reason why this serovar is unable to cause disease in poultry or humans.

It is possible that there has been a key mutational event that reduced virulence in this serovar, reducing selective pressure on the remaining virulence genes, which were free to mutate, as their functionality was no longer required. For example, a primary mutational event (perhaps mediated by a mobile DNA element such as the $1.2 \mathrm{~kb}$ transposase in SPI1 and SPI3), followed by further mutations to other genes in the region, may have occurred in SPI1, and eventually led to the inability of $S$. Sofia to induce systemic disease. More genetic changes may have occurred in the SPI regions over time due to the lack of selective pressure on the genes, which would increase the frequency of mutational events.

The multiple mutations found in the SPI regions of $S$. Sofia do not seem to have abolished its ability to efficiently colonize chickens. S. Sofia isolates are particularly adherent to surfaces, and factors such as physicochemical properties (surface charge and hydrophobicity), fimbriae, flagella and membrane proteins may contribute to its persistence (Chia et al., 2008, 2009; Heuzenroeder et al., 2001). The observation that $S$. Sofia has a significantly reduced ability to invade cells when assayed in vitro is consistent with the 
observed reduction in adherence. However, these observations would seem at to be at odds with finding the bacterium in internal tissues, such as the liver and spleen. It is presumed that there is a correlation between ability to adhere and invade and dissemination to deeper tissues. This study and some recent publications indicate that this may not be the case. Desin et al. (2010) constructed a mutant strain of $S$. Enteritidis that harboured a deletion of SPI1, and demonstrated that although this mutant has significantly reduced cellular invasion, the bacterium can be detected in the livers and spleens of chickens within 1 day of oral challenge. Similarly, Wisner et al. (2010) found that a mutant of $S$. Enteritidis deleted for either the entire SPI1SPI2 region or the SPI2 region alone is able to colonize tissues, albeit at a slightly slower rate than the wild-type. Furthermore, in studies of the prevalent commensal of chickens, Campylobacter jejuni, it has been found that the bacterium is present in the liver and spleen in some birds within $20 \mathrm{~h}$ of challenge (Cox et al., 2007; Meade et al., 2009). Interestingly, as has been observed for $S$. Sofia, $C$. jejuni is a persistent infection frequently observed in poultry at slaughter. Taken together, these studies and the present one indicate that systemic spread of bacteria can occur in the absence of SPI1 and/or SPI2, and that this systemic dissemination does not necessarily induce disease.

In summary, the avirulence of $S$. Sofia is probably not due to a single mutation or deletion event but rather a series of mutations in the genes within the virulence regions (Table 2 ). Further studies of the expression of $S$. Sofia virulence genes (and the functionality of their encoded proteins) may reveal the extent to which the mutations have attenuated the virulence process. Wild-type $S$. Sofia isolates are highly unlikely to regain full pathogenicity because of the accumulated mutations in many important virulence genes (Table 2), and even the chance acquisition of a virulence factor (e.g. a virulence plasmid) will most likely not be sufficient to completely restore $S$. Sofia virulence. Therefore, S. Sofia may be considered somewhat differently from other Salmonella spp. when monitoring salmonellae. Due to its persistence and colonization ability, there may be potential for the future use of $S$. Sofia as an avirulent carriage vector for the delivery of vaccines and other useful products within the chicken gastrointestinal system.

\section{ACKNOWLEDGEMENTS}

We thank Dr Alvin Lee (Food Science Australia, Werribee, Victoria, Australia), Dr Margaret McKenzie (Inghams Enterprises Pty Ltd, Springwood, Queensland, Australia) and Professor Richard Strugnell (The University of Melbourne, Victoria, Australia) for providing bacterial strains.

\section{REFERENCES}

Amavisit, P., Lightfoot, D., Browning, G. F. \& Markham, P. F. (2003). Variation between pathogenic serovars within Salmonella pathogenicity islands. J Bacteriol 185, 3624-3635.
Ben-Barak, Z., Streckel, W., Yaron, S., Cohen, S., Prager, R. \& Tschäpe, H. (2006). The expression of the virulence-associated effector protein gene avrA is dependent on a Salmonella entericaspecific regulatory function. Int J Med Microbiol 296, 25-38.

Blanc-Potard, A. B. \& Groisman, E. A. (1997). The Salmonella selC locus contains a pathogenicity island mediating intramacrophage survival. EMBO J 16, 5376-5385.

Blanc-Potard, A. B., Solomon, F., Kayser, J. \& Groisman, E. A. (1999). The SPI-3 pathogenicity island of Salmonella enterica. J Bacteriol 181, 998-1004.

Buchmeier, N. A. \& Heffron, F. (1989). Intracellular survival of wildtype Salmonella typhimurium and macrophage-sensitive mutants in diverse populations of macrophages. Infect Immun 57, 1-7.

Chadfield, M. S., Brown, D. J., Aabo, S., Christensen, J. P. \& Olsen, J. E. (2003). Comparison of intestinal invasion and macrophage response of Salmonella Gallinarum and other host-adapted Salmonella enterica serovars in the avian host. Vet Microbiol 92, 4964.

Chakravortty, D., Rohde, M., Jäger, L., Deiwick, J. \& Hensel, M. (2005). Formation of a novel surface structure encoded by Salmonella pathogenicity island 2. EMBO J 24, 2043-2052.

Chappell, L., Kaiser, P., Barrow, P., Jones, M. A., Johnston, C. \& Wigley, P. (2009). The immunobiology of avian systemic salmonellosis. Vet Immunol Immunopathol 128, 53-59.

Chia, T. W., Fegan, N., McMeekin, T. A. \& Dykes, G. A. (2008). Salmonella Sofia differs from other poultry-associated Salmonella serovars with respect to cell surface hydrophobicity. J Food Prot 71, 2421-2428.

Chia, T. W., Goulter, R. M., McMeekin, T. A., Dykes, G. A. \& Fegan, N. (2009). Attachment of different Salmonella serovars to materials commonly used in a poultry processing plant. Food Microbiol 26, 853859.

Collier-Hyams, L. S., Zeng, H., Sun, J., Tomlinson, A. D., Bao, Z. Q., Chen, H., Madara, J. L., Orth, K. \& Neish, A. S. (2002). Cutting edge: Salmonella AvrA effector inhibits the key proinflammatory, antiapoptotic NF- $\kappa$ B pathway. J Immunol 169, 2846-2850.

Cooper, G. L., Venables, L. M., Nicholas, R. A. J., Cullen, G. A. \& Hormaeche, C. E. (1992). Vaccination of chickens with chickenderived Salmonella enteritidis phage type 4 aroA live oral Salmonella vaccines. Vaccine 10, 247-254.

Cox, N. A., Richardson, L. J., Buhr, R. J., Northcutt, J. K., Bailey, J. S., Cray, P. F. \& Hiett, K. L. (2007). Recovery of Campylobacter and Salmonella serovars from the spleen, liver and gallbladder, and ceca of six-and eight-week-old commercial broilers. J Appl Poult Res 16, 477480.

Darwin, K. H. \& Miller, V. L. (1999). Molecular basis of the interaction of Salmonella with the intestinal mucosa. Clin Microbiol Rev 12, 405428.

Desin, T. S., Wisner, A. L., Lam, P.-K. S., Berberov, E., Mickael, C. S., Potter, A. A. \& Köster, W. (2010). Evaluation of Salmonella enterica serovar Enteritidis pathogenicity island-1 proteins as vaccine candidates against $S$. Enteritidis challenge in chickens. Vet Microbiol Sep 15 [Epub ahead of print].

Dieye, Y., Ameiss, K., Mellata, M. \& Curtiss, R., III (2009). The Salmonella pathogenicity island (SPI) 1 contributes more than SPI2 to the colonization of the chicken by Salmonella enterica serovar Typhimurium. BMC Microbiol 9, 3.

Dorsey, C. W., Laarakker, M. C., Humphries, A. D., Weening, E. H. \& Bäumler, A. J. (2005). Salmonella enterica serotype Typhimurium MisL is an intestinal colonization factor that binds fibronectin. Mol Microbiol 57, 196-211. 
Elsinghorst, E. A. (1994). Measurement of invasion by gentamicin resistance. Methods Enzymol 236, 405-420.

Fierer, J. \& Guiney, D. G. (2001). Diverse virulence traits underlying different clinical outcomes of Salmonella infection. J Clin Invest 107, 775-780.

Gal-Mor, O. \& Finlay, B. B. (2006). Pathogenicity islands: a molecular toolbox for bacterial virulence. Cell Microbiol 8, 1707-1719.

Galyov, E. E., Wood, M. W., Rosqvist, R., Mullan, P. B., Watson, P. R., Hedges, S. \& Wallis, T. S. (1997). A secreted effector protein of Salmonella dublin is translocated into eukaryotic cells and mediates inflammation and fluid secretion in infected ileal mucosa. Mol Microbiol 25, 903-912.

Gast, R. K. (1994). Understanding Salmonella enteritidis in laying chickens: the contributions of experimental infections. Int J Food Microbiol 21, 107-116.

Gerlach, R. G., Jäckel, D., Stecher, B., Wagner, C., Lupas, A., Hardt, W. D. \& Hensel, M. (2007). Salmonella pathogenicity island 4 encodes a giant non-fimbrial adhesin and the cognate type 1 secretion system. Cell Microbiol 9, 1834-1850.

Ginocchio, C. C., Rahn, K., Clarke, R. C. \& Galán, J. E. (1997). Naturally occurring deletions in the centisome 63 pathogenicity island of environmental isolates of Salmonella spp. Infect Immun 65, 1267-1272.

Hansen-Wester, I., Chakravortty, D. \& Hensel, M. (2004). Functional transfer of Salmonella pathogenicity island 2 to Salmonella bongori and Escherichia coli. Infect Immun 72, 2879-2888.

Harrington, C. S., Lanser, J. A., Manning, P. A. \& Murray, C. J. (1991). Epidemiology of Salmonella sofia in Australia. Appl Environ Microbiol 57, 223-227.

Hensel, M. (2000). Salmonella pathogenicity island 2. Mol Microbiol 36, 1015-1023.

Hensel, M., Shea, J. E., Gleeson, C., Jones, M. D., Dalton, E. \& Holden, D. W. (1995). Simultaneous identification of bacterial virulence genes by negative selection. Science 269, 400-403.

Hentschel, U. \& Hacker, J. (2001). Pathogenicity islands: the tip of the iceberg. Microbes Infect 3, 545-548.

Heuzenroeder, M. W., Murray, C. J., Dalcin, R. M. \& Barton, M. (2001). Molecular Basis of Benign Colonisation of Salmonella Sofia in Chickens. A report for the Rural Industries Research and Development Corporation. https://rirdc.infoservices.com.au/items/ 01-106

Hong, K. H. \& Miller, V. L. (1998). Identification of a novel Salmonella invasion locus homologous to Shigella ipgDE. J Bacteriol 180, 17931802.

Kimbrough, T. G. \& Miller, S. I. (2000). Contribution of Salmonella typhimurium type III secretion components to needle complex formation. Proc Natl Acad Sci U S A 97, 11008-11013.

Klein, J. R. \& Jones, B. D. (2001). Salmonella pathogenicity island 2encoded proteins SseC and SseD are essential for virulence and are substrates of the type III secretion system. Infect Immun 69, 737-743.

Kubori, T., Matsushima, Y., Nakamura, D., Uralil, J., Lara-Tejero, M., Sukhan, A., Galán, J. E. \& Aizawa, S. I. (1998). Supramolecular structure of the Salmonella typhimurium type III protein secretion system. Science 280, 602-605.

Kubori, T., Sukhan, A., Aizawa, S. I. \& Galán, J. E. (2000). Molecular characterization and assembly of the needle complex of the Salmonella typhimurium type III protein secretion system. Proc Natl Acad Sci U S A 97, 10225-10230.

Lawley, T. D., Chan, K., Thompson, L. J., Kim, C. C., Govoni, G. R. \& Monack, D. M. (2006). Genome-wide screen for Salmonella genes required for long-term systemic infection of the mouse. PLoS Pathog 2, el1.

Lowe, G. H. (1962). A2.7.23 ONPG broth. In Cowan and Steel's Manual for Identification of Medical Bacteria, 2nd edn, p. 152. Edited by S. T. Cowan. Cambridge, UK: Cambridge University Press.

Marcus, S. L., Brumell, J. H., Pfeifer, C. G. \& Finlay, B. B. (2000). Salmonella pathogenicity islands: big virulence in small packages. Microbes Infect 2, 145-156.

Meade, K. G., Narciandi, F., Cahalane, S., Reiman, C., Allan, B. \& O'Farrelly, C. (2009). Comparative in vivo infection models yield insights on early host immune response to Campylobacter in chickens. Immunogenetics 61, 101-110.

Mellor, G. E., Duffy, L. L., Dykes, G. A. \& Fegan, N. (2010). Relative prevalence of Salmonella Sofia on broiler chickens pre- and postprocessing in Australia. Poult Sci 89, 1544-1548.

Miki, T., Shibagaki, Y., Danbara, H. \& Okada, N. (2009). Functional characterization of SsaE, a novel chaperone protein of the type III secretion system encoded by Salmonella pathogenicity island 2 . J Bacteriol 191, 6843-6854.

Morgan, E., Campbell, J. D., Rowe, S. C., Bispham, J., Stevens, M. P., Bowen, A. J., Barrow, P. A., Maskell, D. J. \& Wallis, T. S. (2004). Identification of host-specific colonization factors of Salmonella enterica serovar Typhimurium. Mol Microbiol 54, 994-1010.

Morgan, E., Bowen, A. J., Carnell, S. C., Wallis, T. S. \& Stevens, M. P. (2007). SiiE is secreted by the Salmonella enterica serovar Typhimurium pathogenicity island 4-encoded secretion system and contributes to intestinal colonization in cattle. Infect Immun 75, $1524-1533$.

Murli, S., Watson, R. O. \& Galán, J. E. (2001). Role of tyrosine kinases and the tyrosine phosphatase SptP in the interaction of Salmonella with host cells. Cell Microbiol 3, 795-810.

Ochman, H. \& Groisman, E. A. (1996). Distribution of pathogenicity islands in Salmonella spp. Infect Immun 64, 5410-5412.

Ochman, H., Soncini, F. C., Solomon, F. \& Groisman, E. A. (1996). Identification of a pathogenicity island required for Salmonella survival in host cells. Proc Natl Acad Sci U S A 93, 7800-7804.

Pfeifer, C. G., Marcus, S. L., Steele-Mortimer, O., Knodler, L. A. \& Finlay, B. B. (1999). Salmonella typhimurium virulence genes are induced upon bacterial invasion into phagocytic and nonphagocytic cells. Infect Immun 67, 5690-5698.

Porwollik, S., Wong, R. M. \& McClelland, M. (2002). Evolutionary genomics of Salmonella: gene acquisitions revealed by microarray analysis. Proc Natl Acad Sci U S A 99, 8956-8961.

Reichardt, M. \& Rogers, S. (1994). Preparation of genomic DNA from plant tissue. In Current Protocols In Molecular Biology, vol. 1, pp. 21-27. Edited by F. M. Ausubel, R. Brent, R. E. Kinston, D. M. Moore, J. A. Smith \& K. Struhl. New York: John Wiley \& Sons, Inc.

Rickard, S. (1998). Investigations into the pathogenic potential of Salmonella sofia. PhD thesis, RMIT University, Melbourne, Australia.

Rychlik, I., Karasova, D., Sebkova, A., Volf, J., Sisak, F., Havlickova, H., Kummer, V., Imre, A., Szmolka, A. \& Nagy, B. (2009). Virulence potential of five major pathogenicity islands (SPI-1 to SPI-5) of Salmonella enterica serovar Enteritidis for chickens. BMC Microbiol 9, 268.

Shaw, C. \& Clarke, P. H. (1955). A2.7.17 Malonate-phenylalanine medium. In Cowan and Steel's Manual for Identification of Medical Bacteria, 2nd edn, p. 152. Edited by S. T. Cowan. Cambridge, UK: Cambridge University Press.

Sukhan, A., Kubori, T., Wilson, J. \& Galán, J. E. (2001). Genetic analysis of assembly of the Salmonella enterica serovar Typhimurium type III secretion-associated needle complex. J Bacteriol 183, 11591167. 
Tükel, C., Akçelik, M., de Jong, M. F., Şimşek, Ö., Tsolis, R. M. \& Bäumler, A. J. (2007). MarT activates expression of the MisL autotransporter protein of Salmonella enterica serotype Typhimurium. J Bacteriol 189, 3922-3926.

Wallis, T. S. (2006). Host-specificity of Salmonella infections in animal species. In Salmonella Infections: Clinical, Immunological and Molecular Aspects (Advances in Molecular and Cellular Microbiology), pp. 89-116. Edited by P. M. Mastroeni \& D. Maskell. Cambridge, UK: Cambridge University Press.

Wisner, A. L., Desin, T. S., Koch, B., Lam, P. K., Berberov, E. M., Mickael, C. S., Potter, A. A. \& Köster, W. (2010). Salmonella enterica subspecies enterica serovar Enteritidis Salmonella pathogenicity island 2 type III secretion system: role in intestinal colonization of chickens and systemic spread. Microbiology 156, 2770-2781.

Wong, K. K., McClelland, M., Stillwell, L. C., Sisk, E. C., Thurston, S. J. \& Saffer, J. D. (1998). Identification and sequence analysis of a 27-kilobase chromosomal fragment containing a Salmonella pathogenicity island located at 92 minutes on the chromosome map of Salmonella enterica serovar Typhimurium LT2. Infect Immun 66, 3365-3371.

Wood, M. W., Jones, M. A., Watson, P. R., Hedges, S., Wallis, T. S. \& Galyov, E. E. (1998). Identification of a pathogenicity island required for Salmonella enteropathogenicity. Mol Microbiol 29, 883-891.

Zhang, S., Kingsley, R. A., Santos, R. L., Andrews-Polymenis, H., Raffatellu, M., Figueiredo, J., Nunes, J., Tsolis, R. M., Adams, L. G. \& Bäumler, A. J. (2003). Molecular pathogenesis of Salmonella enterica serotype Typhimurium-induced diarrhea. Infect Immun 71, 1-12.

Zierler, M. K. \& Galán, J. E. (1995). Contact with cultured epithelial cells stimulates secretion of Salmonella typhimurium invasion protein InvJ. Infect Immun 63, 4024-4028.

Edited by: V. J. Cid 